\title{
Henri Coudreau e a "vulgarização" amazônica: os índios Juruna, Tapayuna e Parintintin (1895-1896)
}

\section{Henri Coudreau and the Amazonian popularization: the indians Juruna, Tapayuna and Parintintin (1895-1896)}

Matheus Camilo Coelho - Mestrando do Programa de Pós-Graduação em História Social da Amazônia da Universidade Federal do Pará (UFPA). E-mail: mcamilocoelho1@gmail.com.

Alegria Benchimol - Doutora em Ciência da Informação pelo Instituto Brasileiro de Informação em Ciência e Tecnologia (IBICT) em convênio com a Universidade Federal do Rio de Janeiro (UFRJ). Professora Permanente do Programa de Pós-Graduação em Ciência da Informação da Universidade Federal do Pará (UFPA). E-mail: alegria. benchimol@gmail.com.

Elis de Araújo Miranda - Doutora em Planejamento Urbano e Regional, pelo Instituto de Pesquisa e Planejamento Urbano e Regional da Universidade Federal do Rio de Janeiro (IPPUR/UFRJ). Professora do Departamento de Geografia de Campos da Universidade Federal Fluminense (UFF). E-mail: elismiranda10@gmail.com.

\section{Resumo}

Entre 1895 e 1899, o geógrafo francês Henri Coudreau realizou expedições pelo estado do Pará a serviço do governo deste estado a fim de sistematizar informações a acerca da geografia física e da população paraense. Os registros das expedições foram feitos por meio de mapas, desenhos, fotografias e coleta de objetos significativos para os grupos sociais que manteve contato. Além disso, Coudreau tinha o importante papel de vulgarizar informações por meio de seus livros editados na Europa. O presente artigo, por meio de uma pesquisa qualitativa, visa investigar as informações e as imagens de três povos indígenas vulgarizadas nos livros intitulados "Viagem ao Tapajós" e "Viagem ao Xingú", de autoria de Henri Coudreau.

\section{Palavras-chave}

Henri Coudreau. Vulgarização Científica. Povos Indígenas. Ciência na Amazônia.

\begin{abstract}
Between the years of 1895 and 1899, the French geographer Henri Coudreau were on expedition in the Pará state collecting data about physical geography and population's natural wealth. Henceforth, he cataloged the information through maps, drawings, photographs and by collecting substantial objects from social native groups. Furthermore, Coudreau had the important role of Amazonia popularization in Europe, due to his publishing and edition in Europe. Through a qualitative research, this paper aims to investigate the information and images collected from three Brazilian Indigenous Peoples vulgarized by the works of Henri Coudreau, intitled "Viagem ao Tapajós" and "Viagem ao Xingú".
\end{abstract}

\section{Keywords}

Henri Coudreau. Science popularization. Brazilian Indigenous Peoples. Science in the Amazon. 


\section{INTRODUÇÃO}

O século XIX, na Amazônia, foi assinalado pelo grande número de expedições realizadas por exploradores, naturalistas e viajantes que se embrenhavam pelas matas com o intuito de mapear o território, identificar as espécies animais e vegetais, registrar os modos de vida dos povos indígenas e suas técnicas de plantar, caçar, pescar, de produzir objetos e formas de uso do solo, além de coletar objetos referentes aos povos indígenas e amostras da fauna e da flora amazônica.

As expedições realizadas pelos viajantes, em sua maioria, foram financiadas pelo Estado, pelas elites nacionais e/ou por instituições científicas brasileiras, europeias ou norte-americanas. Os líderes dessas missões possuíam formações distintas e ficaram conhecidos como naturalistas. Seus relatos de viagens, que contavam suas experiências nas zonas de contato $^{1}$, foram difundidos por meio de publicações de livros e diários de viagens na Europa e Estados Unidos. Tais narrativas contrapunham a visão do ser "civilizado" frente ao povo "atrasado". Independente da sua classe social ou profissão, o viajante se reconhecia com a "civilização europeia e seus padrões de avaliação dos homens, de acordo com os padrões de êxito ou de fracasso" (LEITE, 1997, p. 10). Assim, as descrições dos viajantes sobre os povos amazônicos foram elaboradas a partir de uma perspectiva eurocêntrica de mundo.

O investimento nessas missões por parte dos governadores do estado do Pará fez parte de um contexto de efervescência do cenário político e científico da Amazônia no final do século XIX. Esse século é marcado pelo desenvolvimento econômico-tecnológico e pelo Imperialismo ${ }^{2}$. A América do Sul, assim como a América Central e o continente africano, foi colocada na dinâmica capitalista como fornecedora de matéria-prima para as indústrias europeias (HOBSBAWN, 2016). Neste contexto, a floresta amazônica emerge como fonte inesgotável de novas matérias-primas e de áreas a serem exploradas e conquistadas, atraindo viajantes e naturalistas de nacionalidade europeia e americana (BENCHIMOL, 2015).

As práticas desenvolvidas por esses viajantes e cientistas geraram representações iconográficas e textuais da natureza e dos habitantes amazônicos, além de coleções "dos três reinos da natureza, trazidos de lugares distantes, de

1 Conceito de Mary Louise Pratt (1999) que se refere ao espaço social no qual atores sociais de culturas diferentes se encontram, se relacionam e se chocam em relações marcadamente assimétricas de coerção, desigualdade radical e de subordinação.

2 Aqui entendido por teoria e atitudes de um centro metropolitano dominante controlando um território distante, e a sua consequência, colonialismo - a implantação de colônias em possessões distantes - eram grandes temas da cultura produzida na França e Inglaterra do final do século XIX e início do século XX (SAID, 1995). 
territórios recém-conquistados pelos impérios europeus, e que tomaram impulso com o surgimento e desenvolvimento de museus, no Velho e Novo Mundo" (BENCHIMOL, 2015, p. 21).

Neste contexto, encontra-se Henri Anatole-Coudreau, geógrafo e viajante francês, que realizou expedições pela Amazônia nas últimas décadas do século XIX. Primeiramente, a serviço do governo francês, e posteriormente, por determinação dos governos republicanos do estado do Pará. Entre 1895 e 1899, comandou cinco expedições patrocinadas pelo governo paraense de Lauro Sodré e Paes de Carvalho, com a finalidade de levantar e realizar estudos geográficos, etnográficos, econômicos, sociais e estatísticos do estado. Os livros de Coudreau, provenientes dessas viagens, podem ser considerados importantes e fecundos documentos acerca do Pará e das populações indígenas na segunda metade dos oitocentos.

Coudreau pertenceu a uma linha de viajantes e exploradores que não estavam associados diretamente a instituições científicas e acadêmicas e que não compartilhavam totalmente do cientificismo e teoria raciais, como pode observarse na sua crença no mito do "bom selvagem" de Rousseau (BENOIT, 2000; FERRET'TI, 2017a). As explorações do francês faziam parte de uma espécie de projeto de colonialismo interno objetivado pelas elites pós-coloniais da América Latina (FERRET'TI, 2017b).

O presente trabalho pretende investigar a vulgarização científica realizada por Henri Coudreau a respeito dos povos indígenas Tapayuna, Parintintin e Jurunua, descritos nas obras "Viagem ao Tapajós" e "Viagem ao Xingú", ambos publicados no Brasil em 1977 pela Editora Itatiaia, na coleção Reconquista do Brasil. Dessa forma, este artigo tem por objetivo identificar as imagens e representações que foram divulgadas nesses dois livros, acerca dos referidos povos, bem como analisar as intencionalidades e as subjetividades que se manifestam nestas representações.

Este artigo é uma pesquisa interdisciplinar, de caráter documental e bibliográfico, com viés histórico, referenciado em aporte teórico da História e da Ciência da Informação. Para investigar sobre a vulgarização realizada por Henri Coudreau, além da bibliografia pertinente sobre divulgação, vulgarização científica e viajantes, também foram consultados documentos do período analisado, como relatórios dos governadores, jornais e em outros livros escritos por Coudreau e outros naturalistas que percorreram o espaço amazônico no mesmo contexto histórico. 


\section{VULGARIZAÇÃO CIENTÍFICA}

José Paes de Carvalho, em mensagem dirigida ao Congresso do Estado d'o Pará, em 15 de abril de 1898, escreveu que Henri Coudreau apresentou um plano de exploração de alguns dos principais rios paraenses e a aplicação deste plano forneceria novos documentos geográficos e novas publicações que concorreriam "efficazmente para vulgarisarem-se em nosso paiz e fora d'elle conhecimentos correctos ácerca do Pará, mal conhecido e mal julgado ainda" (CARVALHO, 1898, p. 22). Além disso, continua o governador, seriam um repositório de importantes dados para a confecção de carta geodésica e cadastral do Estado.

Na fala de Paes de Carvalho se destaca o emprego do termo vulgarizar ao tratar dos resultados oriundos das explorações feitas por Coudreau. Tal como se pode observar, o emprego do termo vulgarização era recorrente nos escritos brasileiros do século XIX, apesar de estar em desuso e o termo atual adequado academicamente ser o de "divulgação científica". A utilização da expressão "vulgarização científica" provém da influência da literatura científica francesa sobre os intelectuais nacionais, haja vista que a origem do termo vulgarisation des Science, segundo Vergara (2008), originou-se na França ainda no século XIX, apropriado por intelectuais e governantes no Brasil, como se lê no discurso do governador do Pará.

Caribé (2015) expõe que a origem da palavra vulgaire vem do latim vulgus que é sinônimo de algo popular, comum. A partir do século XIX, e até os dias de hoje, o termo "vulgarização da ciência" é a expressão utilizada na França para designar, de forma geral, especialmente a atividade de falar de ciência para os leigos (VERGARA, 2008).

A difusão do saber científico, como afirma Bensaude-Vincent e Liz (1995), já era um profícuo gênero literário no século XIX. Na França dos oitocentos ocorre um crescimento da demanda por livros, jornais, peças de teatro e exposições sobre conhecimento científico. $\mathrm{O}$ alvo desses empreendimentos era o público geral, não restrito a cientistas e especialistas. Este crescimento do interesse pelo conhecimento científico decorre de alguns fatores: a) a segunda revolução industrial que "trouxe uma nova ordem na qual a vida material passou a ser ditada por novas capacidades técnicas"; b) o alargamento da instrução pública na França; e c) relaciona-se a este processo, o crescimento do mercado editorial na Europa (KODAMA, 2016, p. 42).

Esse momento de difusão da ciência, propagando lemas como "ciência para todos" e "ciência popular", aconteceu na França entre as décadas de 1850 e 1880 (KODAMA, 2016). O termo "vulgarização" passou a ser adotado, apesar 
de ocorrerem discussões entre os próprios vulgarizadores acerca da melhor expressão a ser utilizada.

A ação de falar de ciência para leigos exige um mediador, este, por sua vez, chamava-se vulgarizador. Este era um "ator social e um mediador cultural datado", pois desempenhava um importante papel na sociedade como um tradutor do conhecimento científico. O período de esplendor dessa prática ocorreu entre a segunda metade do século XIX e os primeiros anos do século XX, até a Primeira Guerra Mundial (KODAMA, 2016).

A vulgarização possuía objetivos claros de traduzir a linguagem utilizada pela comunidade científica para algo mais acessível e mais compreensível os sujeitos comuns. A tradução visada pela vulgarização, como aponta Vergara (2008), tem em si limitações e estas estão relacionadas à restrição da apropriação do conhecimento pelo próprio vulgarizador e a recepção do público, abstração basilar para a ação da vulgarização, mas cuja compreensão depende de fatores como instrução formal e informal, classes sociais e predileções por determinados temas em detrimento de outros. Acrescentamos ainda às limitações da vulgarização científica os limites impostos pelas ideologias e pelo contexto político-econômico no qual as mensagens são veiculadas.

O público era algo fundamental para o vulgarizador, pois esse é o alvo e destinatário da mensagem elaborada por aqueles que desejavam ter suas ideias disseminadas. Contudo, a ideia de grande público esbarra em problemas como classe social, escolaridade e predileções, como dito anteriormente. Não é possível definir o que é o "grande público" sem fazê-lo num plano ideal e de forma datada, no qual as ideologias e as práticas sociais também trabalhem na sua construção, além da identificação dos lugares selecionados para a realização desses eventos. A depender do lugar, o vulgarizador poderia alcançar um determinado público ou afastar este público. Aqueles sujeitos sem instruções, os espaços acadêmicos se tornavam inatingíveis, por exemplo.

No Brasil, a vulgarização teve seu lugar por meio da instalação da imprensa, das instituições museológicas e de obras de viajantes estrangeiros que percorreram o território brasileiro ou que passaram a residir no país ao longo do século XIX e início do século XX. Nesse período, duas características se sobressaíram acerca da vulgarização da ciência no Brasil: os mais notáveis divulgadores eram homens ligados à ciência pela sua profissão ou pelas suas atividades científicas. O segundo atributo era uma hegemonia do interesse nos resultados práticos da ciência predominante da utilização prática da ciência (MOREIRA; MASSARANI, 2002).

Moreira e Massarani (2002, p. 50) apresentam a possibilidade de ter havido algum tipo de difusão de conhecimento científico no Brasil, mesmo que indireto, 
por meio das obras dos viajantes "na medida em que viajavam por lugares remotos do país e tinham interações com uma parcela da população local”, como é possível observar em alguns trechos e comentários encontrados nos seus livros ou relatos das viagens de Henri Coudreau.

Segundo os autores, há ainda outro processo de transmissão, inverso ao já apresentado, no qual os povos nativos transmitiam seus conhecimentos e informações para os naturalistas (MOREIRA; MASSARANI, 2002). Esse modelo de difusão de conhecimento pode ser observado na obra do próprio Coudreau (1977a), quando o mesmo menciona ter sido auxiliado e guiado durante a viagem pelo rio Xingu por dois índios Juruna: Xambi e Laurinda. Estes indígenas foram fontes orais do saber do referido povo acerca da floresta, das formas de uso dos produtos da floresta, das suas práticas e dos costumes alimentares, ritualísticos e sociais dos habitantes da região.

Moreira e Massarani (2002) ressaltam ainda a importância de Emílio Goeldi, então diretor do Museu Paraense, para a "vulgarização científica". Quando Goeldi assumiu o cargo de direção da instituição formulou um novo regulamento, aprovado em 1894, visando a organizá-la e torná-la um centro de estudo e de vulgarização da ciência. No referido regulamento, constam os objetivos da instituição e os meios necessários para consegui-los: “O estudo, o desenvolvimento e a vulgarização da História Natural e Etnologia do Estado do Pará e da Amazônia em particular, do Brazil, da América do Sul e do continente americano em geral" (SODRÉ, 1894, p. 22), se dará por meio de coleções coordenadas e classificadas cientificamente, conferências públicas e por publicações.

Henri Coudreau cumpria um papel de vulgarizador, não de uma produção científica - afinal ele não era um cientista, mas um explorador e viajante a serviço do Estado - mas das riquezas naturais e da cultura humana do Pará no final do século XIX. Seus escritos, mesmo que em francês ${ }^{3}$, foram impressos para difundir saberes e conhecimentos a respeito da Amazônia, sobretudo da paraense, como destacado no excerto, já citado, de Paes de Carvalho (CARVALHO, 1898).

As narrativas descritas nos livros "Viagem ao Tapajós" e "Viagem ao Xingú", apesar de derivarem de relatórios apresentados às autoridades estatais, possuem um caráter educativo, pretendendo difundir saberes acerca da paisagem amazônica e da sua população, aspecto caracterizador dos vulgarizadores do século XIX 4 . Compreendendo Coudreau como um vulgarizador, investigaremos

A primeira tradução de seus livros para o português que encontramos corresponde à década de 1940 (COUDREAU, [194-]).

4 Em carta destinada a Jacques Huber, botânico suíço e diretor do Museu Paraense, de 1907 a 1914, Theodor Koch-Grünberg, etnologista e explorador alemão, cita Coudreau como 
o que Coudreau vulgarizou sobre os povos Tapayuna, Juruna e Parintintin e como Coudreau apresentou ao mundo esses indígenas.

\section{OS ÍNDIOS TAPAYUNA, PARINTINTIN E JURUNA SOB A ÓTICA DE COUDREAU}

A descrição da paisagem amazônica, das riquezas naturais e das populações das regiões visitadas, sobretudo as ocupadas por povos indígenas, é algo comum nos objetivos das expedições de Coudreau e nas obras publicadas do autor, como Viagem ao Tapajós e Xingú. Essas descrições são documentos sobre esses povos e sua cultura nos fins do século XIX e sobre a visão de viajantes, tal como o geógrafo francês, sobre as populações indígenas da Amazônia no referido período.

Em Viagem ao Tapajós e Viagem ao Xingu, destacam-se três desses povos indígenas: os Tapayuna, os Parintintin e os Juruna. Destacamos esses dois livros por apresentarem um volume de informações significativas, por apresentarem descrições importantes produzidas por Coudreau e publicadas nessas duas obras. O geógrafo francês vulgarizou, nas suas obras, descrições e imagens sobre esses três povos, não de forma isenta ou imparcial, mas a partir das lentes culturais europeias do período e da sua crença no mito do "bom selvagem" (BENOIT, 2000; SOUZA FILHO, 2008).

O primeiro povo encontrado, dos três já mencionados, foram os Tapayuna 5 . O seu relato acerca desse referido povo advém das impressões dos Ápiaka, como se pode perceber no trecho abaixo: "os tapanhumas, ao que parece, falam a língua geral, pois os apiacás afirmam que teriam compreendido perfeitamente sua linguagem nos encontros - aliás muito raros [...]" (COUDREAU, 1977b, p. 85). O geógrafo francês no referido excerto utilizou do relato oral dos Apiaká para abordar a língua dos Tapayuna, mas usa o termo "ao que parece" para esclarecer que o que estava a descrever não possuía um rigor científico.

Henri Coudreau apresentou os Tapayuna como "bandidos hereditários e profissionais, em relação aos quais a filantropia é uma ilusão" (COUDREAU, 1977b, p. 86). Essa representação sobre o referido povo indígena se refere à maneira que o povo atacava viajantes que trafegavam pelos rios da região.

referência de informações para a sua futura expedição pelo Pará. Ver: Carta de Theodor KochGrünberg a Jacques Huber. Berlim, 16 de dezembro de 1907. Museu Paraense Emílio Goeldi, Arquivo Guilherme de La Penha, Fundo Jacques Huber, Dossiê Theodor Koch-Grünberg (KOCH-GRÜNBERG, 1907).

5 A antropóloga Daniela Batista de Lima (2014) levanta a hipótese de que os indígenas descritos por Coudreau provavelmente não eram Tapayuna e sim Kayabi, pois estes últimos povos habitavam originalmente a região do rio dos Peixes e do Teles Pires e não os Tapayuna. Por conta da ausência de fontes que comprovem essa afirmação, decidiu-se continuar a denominar o povo encontrado pelo viajante como sendo "Tapayuna". 
Coudreau descreveu que os Tapayuna ficavam em alguma praia ou ribanceira esperando os viajantes passarem e de uma hora para outra surgiam na paisagem, sem armas, sorrindo e fazendo gestos cordiais convidando os forasteiros a atracar. Assim que os viajantes se aproximavam, os referidos indígenas os atacavam com flechas. O geógrafo relatou que a tática de guerra usada pelos Tapayuna não possuía um senso moral ou valor militar, mas consistia no assassinato por traição (COUDREAU, 1977b).

Esse relato dos Tapayuna produzido por Coudreau, como índios violentos e ações contestáveis pela moral em vigor, tal como toda representação, deve ser analisado com cautela. É necessário levar em conta que a produção dele é embasada no relato oral dos Apiaká, sem comprovações empíricas pelo geógrafo. Além disso, o geógrafo desconsidera em seu relato o que os povos amazônicos já haviam sofrido desde os primeiros anos da colonização europeia. Possivelmente, as táticas dos Tapayuna consistiam em formas de proteção do seu território e não simples ataques a estrangeiros.

Esta imagem é fruto de uma leitura do real e é elaborada num processo de escolha primeiramente da fonte primária, os Apiaká, e depois do próprio Coudreau. Os critérios desta seleção não aparecem de forma direta e clara no trecho apresentado, mas pode-se cogitar algumas questões para analisar.

É importante problematizar o real estado da relação entre os Apiaká e os Tapayuna e o quanto de informação eles possuíam, pois como o próprio Coudreau escreveu os dois povos tiveram raros encontros. Além disso, toda a descrição se baseia no "atraso" e nos hábitos selvagens dos Tapayuna. Esta limitação, como pontua Leite (1997), é comum aos viajantes, pois estes trazem em seus relatos a postura do "civilizado" que analisa o "atraso" do nativo - que muitas vezes era reforçado "por uma série de obstáculos linguísticos, culturais e econômicos à compreensão do grupo visitado” (LEITE, 1997, p. 10).

Segundo informações do Instituto Socioambiental (ISA), os Tapayuna viviam inicialmente na região do rio Arinos, próximo ao Tapajós e do município de Diamantino, em Mato Grosso, mas foram expulsos e perseguidos por seringueiros, garimpeiros e madeireiros que se interessavam pelas riquezas naturais do território (ISA, 2017a).

Lima (2014) afirma que ocorreu um genocídio do povo Tapayuna entre os séculos XIX e XX, consequência de políticas estatais visando a ocupação e exploração econômica da Amazônia a partir do boom econômico da borracha, da mineração, da criação das linhas telegráficas e da Marcha para o Oeste. Nas décadas de 1960 e 1970, o referido povo foi vítima de envenenamentos e surtos de gripe que dizimaram a população. Os sobreviventes foram transferidos para 
o Parque Indígena do Xingu e para a Terra Indígena Capoto-Jarina. Em 2010, estimou-se a população em cerca de 160 pessoas dispersas em aldeias nas Terras Indígenas Wawi e Capoto-Jarina (ISA, 2017).

Próximo da fronteira entre Mato Grosso e Pará, entre o rio Arinos e os formadores do São Manoel, Henri Coudreau relatou que habitavam muitas “tribos 'bravas' e 'mansas"” nessa região que até o período da expedição do geógrafo era pouco habitada por não indígenas e quase desconhecida, dentre eles "[...] tapanhumas e nhambiquaras, os paraintintins, os raipexixis ou aipocicis, os bacaris mansos e os bacairis bravos, os cajabis, os paranaretês [...]" (COUDREAU, 1977b, p. 85).

Os termos "bravos" e "mansos" foram categorias de análises usadas por Coudreau ao descrever e construir uma imagem sobre os povos indígenas encontrados. O pensamento do geógrafo, segundo Souza Filho (2008), situava-se entre o Socialismo nascente e o Romantismo de Rousseau, idealizado na figura do "bom selvagem".

Para Coudreau, os melhores homens são os que se mantinham isolados, distantes da civilização, preservando sua liberdade, sua capacidade de escolher o seu destino. Mas essa virtude poderia ser perdida, caso os indígenas se civilizassem rapidamente (SOUZA FILHO, 2008). É possível perceber essa noção em passagens de seu livro, nas quais o francês criticou e ironizou os índios que se associavam aos seringueiros, fazendeiros e aos "civilizados".

Além da característica do "isolamento", os melhores homens não entram em embates com os "civilizados", não são hostis com estes. Como é o caso dos Parintintin, indígenas que viviam no Tapajós, considerados pelo francês como índios mansos, sem conflitos com os civilizados.

Esse povo foi elogiado por Coudreau como sendo "sóbrios, honestos, repletos de qualidades" (COUDREAU, 1977b, p. 32). O elogio, possivelmente, está associado ao seu "isolamento" e sua relação de paz com os civilizados, lembrando o apreço do francês pelo ideal do "bom selvagem”. O geógrafo relatou que os Parintintin viviam dispersos em pequenos grupos na floresta, sem coesão, intencionando fugir dos Munduruku, com os quais estavam em continuada guerra. No entanto, poderia ser encerrado esse período de "isolamento" pelos civilizados, que viriam de forma amigável, como esperava o geógrafo, por interesse nos segredos sobre domínio do referido povo indígena do interflúvio Xingu-Tapajós (COUDREAU, 1977b, p. 31).

Os Parintintin são descritos fisicamente pelo francês como portadores de longas cabelereiras, com corpos pouco pintados e que viviam sem vestimentas.

\footnotetext{
6 Grifos do autor.
} 
Para escrever essa descrição, Coudreau utilizou da memória oral dos habitantes dessa região do Tapajós - índios, ribeirinhos, seringalistas - cuja credibilidade foi contestada até mesmo pelo francês, ao descrever os compridos cabelos que se enrolavam quando chovia: "disse-me gravemente não sei qual excelente sertanejo que, sem dúvida, jamais os tinha visto" (COUDREAU, 1977b, p. 31).

A utilização da memória do "sertanejo" ia contra os preceitos científicos do fim do século XIX, inclusive foi alvo de críticas contundentes de Arthur Vianna em uma coluna no Jornal "O Pará” no ano de 1898. Após apresentar alguns trechos de Coudreau (1977b, p. 31-32) como "segundo alguns moradores do Jamanxim e do Crepori, os parintintins seriam mais susceptíveis [...]" e "Dizse que falariam uma língua quase igual à dos mundurucus", Vianna (1898, grifos do autor) questionou "haverá por ventura sciencia quando se firma o que se escreve com diz-se, parece, segundo as pessôas etc.?".

Essa crítica desvelada à falta de rigor científico de Coudreau não é uma questão incomum ao trabalho do vulgarizador, pois é inerente ao processo de vulgarização a tradução de conceitos, termos e de conteúdo etnográfico e a dificuldade de manter a mesma precisão da comunidade científica na produção de conhecimento.

Atualmente, os Parintintin, nome esse possivelmente atribuído pelos Munduruku, integram o conjunto de grupos menores que se autodesignam Kagwahiva. No século XIX, foram expulsos pelos civilizados e pelos Munduruku do rio Tapajós, espalhando-se na direção oeste rumo ao rio Madeira, onde residem atualmente e foram "pacificados" por Curt Nimuendajú entre 1922 e 1923. Hoje, a maior parte dos Parintintin vivem em duas Terras Indígenas, Ipixuna e Nove de Janeiro, situadas no município de Humaitá, no Estado do Amazonas, e que contam com uma população de 54 e 80 pessoas, respectivamente (ISA, 2017b).

É possível apreender que a descrição dos Parintintin, tal como a dos Tapayuna, vulgarizada por Coudreau, não foi elaborada como uma simples representação da realidade concreta. A representação do referido povo indígena perpassa as ideologias contidas no pensamento do geógrafo - a crença no mito do "bom selvagem" e o etnocentrismo - e o uso de fontes orais e da memória coletiva.

As descrições de Henri Coudreau acerca dos Tapayuna e dos Parintintin foram marcadas pela subjetividade, pelo etnocentrismo, por ideários culturais que alteravam as visões dos sujeitos locais e estrangeiros e por aspectos políticos, econômicos, culturais e sociais. 
Coudreau não entrou em contato direto com esses povos, e esse fato não pode ser desconsiderado quando se analisa as descrições permeadas de subjetivismo e idealismo, típico de um defensor das ideias de Rousseau do "bom selvagem". Se comparadas com os primeiros relatos, a imagem produzida por Coudreau acerca dos Juruna é mais densa e detalhada, influenciada pelo contato que o francês teve com estes indígenas.

Em 1896, Coudreau embarcou em nova expedição novamente a serviço do governo do Pará. O geógrafo percorreu o rio Xingu e deparou-se com a grave situação vivenciada pelo povo Juruna, que então fugia dos civilizados e dos índios inimigos.

Coudreau reporta que os Juruna habitavam o Xingu na região entre a Praia Grande e a Pedra Seca. No passado, "uns vinte anos", eram numerosos e distribuíam-se em cerca de 18 malocas, cada uma com seu referido tuxaua. Quando da visita do geógrafo, seu número havia sido a reduzido para "no máximo uns 150, entre mansos, civilizados e errantes” (COUDREAU, 1977a, p. 37).

Os Juruna, ou como se autodenominam Yudjá, habitam a região do Xingu desde pelo menos o século XVII. Atualmente, este povo está dividido em duas partes: uma reside na região historicamente ocupada do médio Xingu, na Terra Indígena Paquiçamba e o entorno, enquanto a outra parte habita no alto curso do mesmo rio, no Parque Indígena do Xingu. Essa população sofreu um decréscimo acentuado no século XIX devido à exploração da borracha, como mencionado por Coudreau. Em censo de 2001, o povo Juruna/Yudjá consistia de cerca de 270 pessoas (ISA, 2017c).

Os Juruna viviam dispersos ao longo do rio Xingu e muitos deles fugindo de povos indígenas rivais e de civilizados, como informou Coudreau. Segundo o geógrafo, esse povo trabalhava anteriormente para os civilizados, principalmente nas propriedades dos irmãos Miranda, mas fugiram dos seus patrões, em "carajazada", que segundo o francês significava que estavam "caminhando ao acaso, despistando suas idas e vindas, pilhando e matando para se vingarem de injustiças imaginárias ou reais que os civilizados lhes teriam feito" (COUDREAU, 1977a, p. 51).

Neste excerto, Coudreau não havia entrado ainda em contato com os Juruna fugidos. Posteriormente, na mesma viagem, se compadeceu da qualidade de penúria com a qual esses índios administravam suas vidas. Alguns, inclusive, somaram-se à tripulação e foram tratados como "filósofos".

Apesar da admiração posterior que o geógrafo teria ao povo Juruna, a primeira descrição gerada foi a de guerreiros, não confiáveis e que mereceriam, se atacassem a missão científica, um alvejar de tiros dos rifles dos "civilizados". 
Apesar da apreensão da tripulação, de forma geral, os Juruna foram apresentados por Coudreau como índios "mansos" que fugiam dos índios "bravos" e dos civilizados que objetivavam explorar o seu trabalho e seus saberes. Esse povo estava sempre fugindo pelas matas, deixando rastros e indícios de sua passagem pelas praias e ilhotas ao longo do rio Xingu.

Possivelmente correlacionada ao aspecto de fugitivos, a representação construída dos Juruna por Coudreau é de um povo "medroso". Esta impressão poderia gerar a ironia do francês, como a de descrever as táticas adotadas pelo citado povo para fugir dos Karajá: os Juruna escolhiam pequenas ilhas, para facilitar o desmatamento, que ajudava avistar de longe a chegada de qualquer inimigo e assim poder fugir, ironizou o geógrafo, nas mais "heróicas remadas na mais ligeira das ubás" (COUDREAU, 1977a, p. 54).

Ao longo de toda a expedição, Coudreau deparou-se com alguns Juruna errantes e malocas abandonadas; de uma em especial, a de Turiá, próximo a Cachoeira dos Taperas, o francês coletou "diferentes objetos e utensílios que os Juruna, ao se mudarem, lá deixaram” (COUDREAU, 1977a, p. 65).

Como prática comum entre os viajantes estrangeiros ao adentrar as matas e navegar pelos rios amazônicos, Coudreau contratou um casal de índios da região, os Juruna Xambi e Laurinda, que foram "juntamente com a carta de Steinen, nossos guias de viagem", como confessou (COUDREAU, 1977a, p. 54). Os Juruna eram antigos habitantes da região e possuíam saberes sobre outros povos indígenas e a respeito dos rios, dos igarapés e das matas que compõem a paisagem do Xingu. Além de guias, o casal Juruna foi importante fonte acerca saber tradicional dos Juruna e dos Karajá. O relato da viagem ao Xingu é permeado por passagens no qual o casal de Juruna identifica ubás, malocas, fogueiras e áreas de extração de madeiras do seu povo.

Todavia, o convívio de Henri Coudreau com sua tripulação, formada por indígenas e não indígenas, não era um recôncavo de harmonia, como desabafou o francês afirmando que a viagem ao Xingu estava sendo desagradável, por problemas com os membros da expedição. Coudreau chegou a aconselhar: "tomem cuidado também com a intromissão do mestiço indígena! Viajem sozinhos, ou com verdadeiros brasileiros de educação e cultura médias. cerquemse, tanto quanto possam de paraenses..." (COUDREAU, 1977a, p. 70). No desabafo do francês não há menções aos nomes de Xambi e Laurinda, mas como já mencionado, os mesmos eram de origem Juruna e foram representados na gravura vestidos como civilizados, podendo ser enquadrados como "mestiços indígenas" e não na categoria de "paraenses", que seriam brasileiros de educação e culturas médias, ribeirinhos e proprietários de terra. 
Em 1² de setembro de 1896, Coudreau e sua comitiva percorriam o vasto rio Xingu, atravessando suas cachoeiras, quando de repente, um som familiar os atraiu: um cachorro latia numa praia. O cachorro era manso e pertencia ao índio Juruna Joaquim Pena, “o pobre 'rei exilado' do alto Xingu”, segundo duas "velhas" que ali estavam vigiando o cão (COUDREAU, 1977a, p. 75).

Essas mulheres não fugiram à aproximação da comitiva de Henri Coudreau, apenas gritavam rumo à floresta avisando a chegada da expedição. Em pouco tempo, chegou manobrando uma pequena ubá o próprio Joaquim Pena. Com a chegada de Pena, os dois iniciam um diálogo, transcrito pelo francês, recheado de crítica social à precária situação dos Juruna e de admiração, por parte de Coudreau, ao saber daquele "velho Taxaua".

Primeiramente, Joaquim Pena assinalou sua situação de "nômade" e justificou que "os senhores lá de baixo" (provavelmente proprietários) o obrigaram a buscar a sua liberdade. E desabafou Pena:

Nossa sina é a de estarmos sempre em fuga. Antigamente, a gente fugia dos índios bravos; agora, dos civilizados, nossos queridos protetores. Mas logo estes senhores não poderão proteger quem quer que seja dos nossos: o último dos jurunas não demorará a levar para sempre a alma da raça, em qualquer cova rasa, sob alguns punhados de terra natal (COUDREAU, 1977a, p. 76).

A partir deste excerto, identifica-se na transcrição de Henri Coudreau a fala de um índio "civilizado", como descreve o francês, que "exprime-se com facilidade num português corrente e claro" (COUDREAU, 1977a, p. 75). Provavelmente foi da sua capacidade retórica que surgiu a admiração de Coudreau por Joaquim Pena a ponto de chamá-lo de "meu velho filósofo". Pena era um homem consciente da opressão a qual vivia seu povo e marcava seu diálogo com uma forte crítica a essa situação.

Na obra Viagem ao Xingú, Joaquim Pena é o único indígena que tem sua fala transcrita, os outros, como por exemplo, Laurinda e Xambi, suas opiniões restringem-se a referências citadas pelo francês. Pena possuía uma personalidade forte, pois mesmo após o diálogo com o viajante francês não estava completamente convencido. Era necessário Coudreau mostrar seus rifles e prometer que deixaria o Juruna e sua família no porto de uma roça que eles tinham no interior (COUDREAU, 1977a).

Henri Coudreau, ao percorrer o rio Xingu, deparou-se com a penúria e a precária condição humana a qual se encontravam os povos indígenas da região. Os causadores das moléstias eram os comerciantes que se embrenhavam pela floresta, tirando os índios do seu estado de "bom selvagem" e assimilando- 
os a uma lógica capitalista desigual, que objetivava explorar o seu trabalho e os conduziria a uma situação miserável. Como afirmou: “o bânia e o mascate assentam-se sobre as covas funerárias dos índios há pouco mortos por causa deles, senão por eles próprios. E ficam zombando" (COUDREAU, 1977a, p. 80).

Coudreau era um crítico das ideias que associavam as práticas de comércio numa região como forma de abrandar e refrear os costumes, aspecto de sua formação política (FERRETTI, 2017a). Como havia observado no Xingu, os comerciantes não civilizavam os índios, tão pouco educavam seus costumes, apenas queriam explorar seu trabalho, vender objetos e tirar proveito da situação complexa de opressão vivida pelos povos indígenas na Amazônia no final do século XIX.

\section{CONSIDERAÇÕES FINAIS}

Estudar as expedições do geógrafo francês Henri Coudreau aos rios Tapajós e Xingu, bem como a produção de uma imagem dos povos amazônicos a ser "vulgarizada" para o resto do mundo, colocou em cena questões importantes para o entendimento da visão de mundo daquele momento, como, por exemplo, que as ideias são socialmente e historicamente situadas, bem como evidenciou a visão pessoal de Coudreau - a crença do mito do "bom selvagem" - e de uma demanda do patrocinador da viagem, o governo do estado do Pará, de "vulgarizar" certos conhecimentos e informações sobre a Amazônia paraense, com ênfase nos aspectos geológico, geomorfológico e a localização das áreas ocupadas pelos povos indígenas, seus costumes e domínios de técnicas de plantio, de caça e pesca.

Os livros de Henri Coudreau, sobretudo Viagem ao Tapajós (COUDREAU, 1977b) e Viagem ao Xingú (COUDREAU, 1977a), não se restringem a compêndios de informações sobre o Pará no século XIX ou tão pouco são fidedignos retratos da realidade de algumas regiões paraenses no referido século. As duas aludidas obras são documentos construídos pelo autor com objetivos específicos, ilustradas com gravuras elaboradas após o retorno à França. A elaboração dos conteúdos dos livros parte de um pensamento social etnocêntrico da época e que influencia até a presente data a imagem que o brasileiro de instrução mediana possui sobre as populações indígenas. Nessa perspectiva, Coudreau "vulgarizou" o Pará por meio de narrativas e representações visuais que descreveram uma imagem dos povos indígenas, que introjetou a forma como o governo republicano enxergava e queria que o mundo percebesse os indígenas dos rios Tapajós e Xingu e de como o próprio viajante classificava e compreendia as ações desses sujeitos. 
As intencionalidades e as subjetividades das descrições de Coudreau se manifestaram claramente nas representações dos povos Tapayuna, Parintintin e Juruna. Os índios hostis, como os Tapayuna, aqueles que não aceitam a "civilização", foram julgados pelo francês como bandidos que não possuíam nenhum senso de misericórdia com as outras pessoas. Enquanto aqueles que possuíam um bom relacionamento com os civilizados, foram elogiados por suas qualidades morais, caso dos Parintintin, ou por sua beleza e inteligência, caso do Juruna.

A obra de Henri Coudreau é um compêndio de construções e informações sobre a realidade do século XIX. No presente artigo, investigamos a vulgarização de imagens de três povos indígenas destacados por ele, mas não se encerram, apenas nesta questão, as possibilidades de pesquisa. Estudos sobre a presença do comércio, a formação de coleções etnográficas, as atividades dos indígenas nos rios Tapajós e Xingu nos fins do século XIX são temáticas que necessitam de investigação e vir à tona. Contudo, é importante compreender Coudreau como um vulgarizador que cumpria objetivos propostos pelo governo paraense e que difundia saberes que atendiam à visão oficial do Estado e ao pensamento social etnocêntrico. Importa ressaltar, ainda, que estas visões sobre os indígenas amazônicos, disseminadas por viajantes no século XIX, também orientam as políticas públicas para os indígenas, elaborados pelos agentes do Estado brasileiro na atualidade.

\section{REFERÊNCIAS}

BENCHIMOL, A. Resgate e ressignificação da pesquisa no Museu

Paraense Emílio Goeldi: presença e permanência de cientistas estrangeiros (1894-1914) na produção científica de autores atuais (1991-2010). Orientadora: Lena Vania Ribeiro Pinheiro. 2015. 179 f. Tese (Doutorado em Ciências da Informação) - Instituto Brasileiro de Informação em Ciência e Tecnologia/ Universidade Federal do Rio de Janeiro, Rio de Janeiro, 2015.

BENOIT, S. Henri Anatole Coudreau (1859-1899): dernier explorateur français en Amazonie. Paris: L'Harmattan, 2000.

BENSAUDE-VINCENT, B.; LIZ, L. A public for science. The rapid growth of popularization in nineteenth century France. Réseaux, Paris, v. 3, n. 1, p. 75-92, 1995.

CARIBÉ, R. C. V. Comunicação Científica: reflexões sobre o conceito. Informação \& Sociedade: Estudos, João Pessoa, v. 25, n. 3, p. 89-104, set./dez. 2015. 
CARVAlHO, J. P. Mensagem dirigida ao Congresso do Estado do Pará pelo Dr. José Paes de Carvalho, Governador do Estado, em 15 de abril de 1898, apresentando a proposta a de orçamento da receita e despeza para o exercicio de 1898-1899. Belém: Typ. do Diário Official, 1898.

COUDREAU, H. Viagem ao Tapajós: 28 de julho de 1895 - 7 de janeiro de 1896. São Paulo: Companhia Editora Nacional, [194-]. 288 p., vol. 208. (Brasiliana, Acervo da Fundação da Biblioteca Nacional - Brasil).

COUDREAU, H. Viagem ao Xingú. Tradução: Eugênio Amado; Apresentação: Mário Guimarães Ferri. Belo Horizonte, Itatiaia; São Paulo: Ed. da Universidade de São Paulo, 1977a.

COUDREAU, H. Viagem ao Tapajós. Tradução: Eugênio Amado; Apresentação: Mário Guimarães Ferri. Belo Horizonte, Itatiaia; São Paulo: Ed. da Universidade de São Paulo, 1977b.

FERRETTI, F. Tropicality, the unruly Atlantic and social utopias: the French explorer Henri Coudreau (1859-1899). Singapore Journal of Tropical Geography, [S. l.]. v. 38, n. 3, p. 332-349, 2017a.

FERRETTI, F. Imperial ambivalences. Histories of lady travellers and the French explorer Octavie Renard-Coudreau (1867-1938). Geografiska Annaler: Series B, Human Geography, Estocolmo, v. 99, n. 3, p. 238-255, 2017 b.

HOBSBAWM, Eric. A era dos impérios. 20. ed. Rio de Janeiro: Paz e Terra, 2016.

INSTITUTO SOCIOAMBIENTAL. Tapayuna. São Paulo: ISA, 2017a. Disponível em: https://pib.socioambiental.org/pt/povo/tapayuna. Acesso em: 15 dez 2017.

INSTITUTO SOCIOAMBIENTAL. Parintintim. São Paulo: ISA, 2017b. Disponível em: https://pib.socioambiental.org/pt/Povo:Parintintim. Acesso em: 15 dez 2017.

INSTITUTO SOCIOAMBIENTAL. Yudjá/Juruna. São Paulo: ISA, 2017c. Disponível em: https://pib.socioambiental.org/pt/Povo:Yudj\%C3\%A1/Juruna. Acesso em: 15 dez. 2017.

KOCH-GRÜNBERG, T. [Correspondência]. Destinatário: Jacques Huber. Berlim, 16 dez. 1907.1 carta.

KODAMA, K. A vulgarização científica nas obras de Louis Figuier e suas traduções no Brasil. In: GOMES, A. M. C.; HANSEN, P. S. (org.). Intelectuais mediadores: práticas culturais e ação política. 1ed. Rio de Janeiro: Civilização Brasileira, 2016. v. 1, p. 41-65. 
LEITE, M. L. M. Livros de viagem: 1803-1900. Rio de Janeiro: Editora UFRJ, 1997.

CARIBÉ, R. C. V. Comunicação Científica: reflexões sobre o conceito. Informação \& Sociedade: Estudos, João Pessoa, v. 25, n.3, p. 89-104, set./dez. 2015

LIMA, D. B. Os Tapayuna na História. Campos - Revista de Antropologia, v.15, n.2, p.43-69, 2014.

MENDONÇA, A. Administração do Dr. Lauro Sodré. Belém: Typ. do Diário Official, 1897. (Acervo da Fundação da Biblioteca Nacional - Brasil).

MOREIRA, I.; MASSARANI, L. Aspectos históricos da divulgação científica no Brasil. In: MASSARANI, L.; MOREIRA, I; BRITO, M. F. (org.). Ciência e público: caminhos da divulgação científica no Brasil. 1. ed. Rio de Janeiro: Casa da Ciência, 2002. v. 43, p. 43-62.

PRATT, M. L. Os olhos do império: relatos de viagem e transculturação. São Paulo: EDUSC, 1999.

SAID, E. Cultura e imperialismo. São Paulo: Companhia das Letras, 1995.

SODRÉ, L. Mensagem dirigida pelo Snr. Governador Dr. Lauro Sodré ao Congresso do Estado do Pará em sua reunião em $1^{\circ}$ de fevereiro de 1896. Belém: Typ. do Diário Official, 1896.

SODRÉ, L. Regulamento do Museu Paraense, 2 de julho 1894. Boletim do Museu Paraense de História Natural e Etnografia (Museu Goeldi). Belém: Tip. A. Silva \& Cia., v. 1, n. 1. p. 22-27, set. 1894, p. 22.

SOUZA FILHO, D. Os retratos dos Coudreau: índios e miscigenação através das lentes de um casal de visionários que percorreu a Amazônia em busca do "bom selvagem” (1884-1899). 2008. 219 f. Dissertação (Mestrado em História) - Instituto de Filosofia e Ciências Humanas, Universidade Federal do Pará, Belém, 2008.

VERGARA, M. R. Contexto e conceitos: história da ciência e "vulgarização científica" no Brasil do século XIX. Interciencia, Caracas, v. 33, n. 5, p. 324330, maio 2008 .

VIANNA, A. As viagens de Mr. Coudreau. O Pará, Belém, ano 1, n.164, 16 jun. 1898. 
